\title{
COMENTARIO
}

\section{Un nuevo modelo de desarrollo y de economía}

\author{
José M. Margenat Peralta, S. I.
}

En su habitual mensaje para la Jornada mundial de la paz de 1 de enero de 2013 -este año la $46^{\circ}$-, el Papa comienza diciendo que: "cada nuevo año trae consigo la esperanza de un mundo mejor". Este año no ha sido fácil para la paz; así lo reconoció también Benito XVI en su más reciente Discurso al cuerpo diplomático acreditado ante la Santa Sede (7 de enero de 2013). La catolicidad sirve a la Iglesia para iluminar la situación del mundo y la conciencia de tantas personas, hombres y mujeres "de buena voluntad" según la expresión de Juan XIII, de feliz recordación. Existía, para papa Roncalli, una "estrecha relación entre Dios y el deseo ardiente del hombre de cualquier época de conocer la verdad, de practicar la justicia y vivir en paz" (Pacem in terris). Es ésta también la convicción hondamente sentida y reiteradamente expresada por papa Ratzinger: el deseo de verdad y de justicia que anida en las personas, en la humanidad toda, tiene una orientación intrínseca hacia el conocimiento y el reconocimiento de Dios como verdad racionalmente accesible para el conocimiento humano. Este acceso a la verdad del hombre en la verdad de Dios no sólo es posible para aquél, sino que sólo esta verdad doblemente imbricada posibilita una verdadera concepción y logro del desarrollo humano, el que ha venido en llamarse desarrollo humano integral, del que la paz forma parte como don y como tarea.

\section{Un nuevo modelo de desarrollo humano integral}

El mensaje de la Jornada mundial de la paz fue presentado el 14 de diciembre por el cardenal Peter Turkson, presidente de Justicia y Paz. Según este mensaje, la paz no es ni un sueño ni una utopía, puesto que se funda en un desarrollo integralmente comprendido que afecta a toda la persona y a todas las personas. Éste es el modelo de desarrollo humano integral sobre el que ya tratamos ampliamente en nuestra revista tras la aparición de la encíclica Caritas in veritate. ${ }^{1}$

${ }^{1}$ Revista de Fomento Social 64 (2009) 623-734; 65 (2010) 189-204. 
En un tiempo marcado por la mundialización -con conflictos y con aspectos positivos y negativos- hace falta un compromiso renovado por el bien común y por el desarrollo de todo el hombre y de todos los hombres (Pablo VI, Populorum progressio). A este compromiso se oponen factores económicos y culturales: no sólo las desigualdades crecientes entre ricos y pobres, sino también una difusa mentalidad egoísta e individualista. Frente a un capitalismo financiero sin regulación, que deriva de ese individualismo el mensaje reafirma el modelo de desarrollo que la Iglesia viene defendiendo en los últimos cincuenta años, que gira sobre estos dos ejes, comunión y reconciliación. ${ }^{2}$

El mensaje se pronuncia por un modelo de desarrollo, así como por una nueva visión de la economía. El desarrollo integral, solidario y sostenible, así como el bien común, exigen una correcta escala de valores, que sólo se pueden estructurar teniendo a Dios como referencia última. Los muchos medios o bienes, necesarios para el desarrollo, deben ser usados según la perspectiva de la vida buena, de la conducta recta que reconoce la primacía de la dimensión espiritual y del compromiso por el bien común.

\section{La crisis como una ocasión de discernimiento a partir de un humanismo abierto a la trascendencia}

La actual crisis financiera y económica, que ha tenido como efecto un aumento de las desigualdades, sólo se superará con imaginación social, como pronosticaba Pablo VI (Octogesima adveniens), con personas, grupos e instituciones que promuevan la vida, favorezcan la creatividad humana y aprovechen la crisis como una ocasión de discernimiento (Mensaje, n. 5).

El Papa realiza implícitamente una crítica radical del neoliberalismo, expansivo desde finales de los años 1980 y plasmado en el llamado "consenso de Washington", 3 cuando se refiere a un modelo económico que postula la maximización del beneficio y de un consumo individualista, egoísta desaforado y competitivo. A este individualismo egoísta opone la lógica del

\footnotetext{
${ }^{2}$ Revista de Fomento Social 66 (2011) 753-786; 67 (2012) 135-145. En estos números hubo comentarios de I. Camacho, J. Loring y P. Foglizzo.

${ }^{3}$ El llamado "Consenso de Washington" fue formulado originalmente por John Williamson (1989) en What Washington Means by Policy Reform; en él se reflejaba lo que se entendía como reforma de las orientaciones políticas, es decir una relación de políticas económicas consideradas durante los años 90 por los organismos financieros internacionales y centros económicos con sede en Washington.
} 
don de uno mismo, de las propias capacidades intelectuales, de la propia iniciativa, puesto que un desarrollo económico sostenible, es decir, auténticamente humano, necesita del principio de gratuidad como manifestación de fraternidad y de la lógica del don (Mensaje, n. 5).

Este modelo de desarrollo humano integral, y por eso alternativo al actualmente dominante, reclama un fundamento y una visión. En efecto, ¿̇cómo se puede llevar a cabo un diálogo auténtico cuando ya no hay una referencia a una verdad objetiva y trascendente? En este caso, ¿̇cómo se puede impedir que la violencia, explícita u oculta, no se convierta en la norma última de las relaciones humanas? En realidad, sin una apertura a la trascendencia, la persona cae fácilmente en el relativismo, resultándole difícil actuar de acuerdo con la justicia y trabajar por la paz. En una frase del mensaje, que a algunos puede parecer excesiva, se afirma con radicalidad:

Una condición previa para la paz es el desmantelamiento de la dictadura del relativismo moral y del presupuesto de una moral totalmente autónoma, que cierra las puertas al reconocimiento de la imprescindible ley moral natural inscrita por Dios en la conciencia de cada hombre (Mensaje, n. 2).

El mensaje subraya la necesidad inaplazable de un nuevo humanismo que no niegue ni excluya "a priori" la dimensión trascendente de la persona. Este humanismo funda la visión de la integridad de la persona humana y hace que la paz aparezca como algo natural, como un deseo inscrito como posibilidad en la ley moral natural inscrita en la conciencia de cada hombre, que lleva a éste a reconocer que todas las personas forman parte de una sola familia humana, en esa triple dimensión -personal, comunitaria y transcendente- que impide una visión reductora y relativista del ser humano.

La construcción de la paz pasa siempre por la protección de los derechos fundamentales de la persona, constantemente inspirada por la dignidad trascendente y la realidad natural de la persona humana $A$ veces, especialmente en Occidente se producen equívocos sobre el significado de estos derechos, que se polarizan en una afirmación exagerada y autorreferencial de la autonomía de la persona, cerrada al encuentro con Dios y con los demás. Por el contrario, la defensa auténtica de los derechos humanos sólo se puede hacer desde un humanismo abierto, un humanismo que contemple al hombre en su integridad personal y comunitaria.

La paz es, al mismo tiempo, don de Dios y tarea del hombre, puesto que exige la respuesta libre y consciente de éste. Ésta es la razón del título del mensaje de este año: Bienaventurados los que trabajan por la paz, tarea y responsabilidad, también para las autoridades políticas, que tienen la obligación de resolver los 
conflictos que siguen ensangrentando a la humanidad (todos ellos en África- que el citado Discurso al cuerpo diplomático enumera: Siria, Líbano, Irak, África subsahariana, África del norte, Mali, Cuerno de África, República Centroafricana, Egipto, República democrática del Congo, Nigeria).

\section{Educación y liderazgo para construir la paz}

Para la construcción de la paz por aquellos que trabajan por ella el mensaje señala dos vías: la educación, puesto que ya que la crisis económica y financiera actual se ha desarrollado porque se ha absolutizado con demasiada frecuencia el beneficio en perjuicio del trabajo y porque se ha preferido la economía financiera en vez de la economía real. ${ }^{4}$ Para cambiar esta situación, hay que educar insistentemente en la capacidad de resistencia a la tentación del interés particular cortoplacista, así como en la orientación hacia el bien común. Para establecer la justicia no basta con buenos modelos económicos, aunque sean necesarios; la justicia solamente se realiza si hay personas justas. Construir la paz significa educar a las personas a combatir la corrupción, la criminalidad, la producción y el tráfico de drogas, así como a evitar divisiones y tensiones que debilitan a las sociedades, obstaculizan el desarrollo y hacen inviable la convivencia pacífica. Esta primera vía educativa se completa con la muy urgente de la formación de líderes que guíen en el futuro las instituciones públicas (Mensaje, n. 6). También la Unión Europea necesita líderes clarividentes que tomen difíciles decisiones para enderezar su economía y poner las bases sólidas de su desarrollo. En una clara referencia no sólo a Alemania, el Papa afirmaba que aunque algunos países, ellos solos, posiblemente irían más rápido, todos juntos irán ciertamente más lejos. El índice diferencial entre los tipos financieros puede constituir una preocupación, pero las crecientes diferencias entre un pequeño número de personas y de países, cada vez más rico, y un gran número, irremediablemente más pobre, debería despertar una preocupación mayor. Benito XVI dijo en el citado discurso de 7 de enero: Se trata, en una palabra, de no resignarse al «spread de bienestar social», ${ }^{5}$ mientras se combate el financie-

\footnotetext{
${ }^{4}$ Cfr. Pontificio Consejo de Justicia y PAz (2011) Para una reforma del sistema financiero y monetario internacional: RFS 66, 753-771.

${ }^{5}$ En italiano se usa frecuentemente esta expresión inglesa, spread, referida a la diferencia entre el precio de compra y el de venta de un activo financiero, margen con el que se mide la liquidez del mercado, aunque también se usa para referirse a la combinación estratégica de compra y venta de una opción de compra o de una opción de venta sobre el mismo activo subyacente y el mismo vencimiento pero con distintos precios de ejercicio.
} 
ro. Los cristianos, por último, deben ser conscientes de que no deben escapar al mundo, deben comprometerse con él y participar en los asuntos del mundo, se llamen éstos "parlamento" o "bolsa", siendo responsables de los más pobres y los más vulnerables y colaborando con los demás, también los no creyentes o las personas de otras religiones, ya que los fines de la justicia son compartidos por tantos otros hombres y mujeres.

En resumen, un mensaje dotado de claridad conceptual y radicalidad exigente, y, por lo mismo, capaz a de abrirse a un diálogo con muchas personas de buena voluntad. Ésta es la intención de estos mensajes de la Jornada mundial de la paz que cada año publica la Santa Sede. 